\title{
Truncated Microstrip Patch Antenna with DGS Based on Double Looped CSRR Arrays for Enhancement of Bandwidth
}

\author{
V.G. Ajay ${ }^{1}$, Thomaskutty Mathew ${ }^{2}$, N.V.Krishna Prasad ${ }^{3}$, M.S.S.R.K.N.Sarma ${ }^{4}$, \\ ${ }^{1}$ School of Technology and Applied Sciences, M. G. University Regional Centre, Edappally, Kochi, Kerala, India \\ 2,3,4 Department of Physics, School of Technology, GITAM University, \\ Bengaluru Campus, India
}

\begin{tabular}{l}
\hline \hline Article Info \\
\hline Article history: \\
Received Feb 25, 2020 \\
Revised Oct 3, 2020 \\
Accepted Oct 5, 2020 \\
\hline
\end{tabular}

Keyword:

Metamaterials, Double Looped Complementary Split Ring Resonator, Microstrip patch antennas

\begin{abstract}
This paper presents a novel method for the design of truncated microstrip patch antenna with Defected Ground Structure (DGS) based on Double Looped Complementary Split Ring Resonator (CSRR) arrays for enhancement of bandwidth. The proposed antenna is suitable for WLAN/Wi-Fi, RFID applications. A truncated microstrip patch antenna without DGS was initially designed for a resonant frequency of $2.86 \mathrm{GHz}$ having a bandwidth of $95.6 \mathrm{MHz}$. By integrating a new Double Looped CSRR array (DLCSRR) structure on the ground plane, resonant frequency of the antenna is shifted to $2.47 \mathrm{GHz}$ and also the bandwidth is enhanced to 202.5MHz. By implementing DLCSRR array structure on the ground plane size reduction and bandwidth enhancement of $52.79 \%$ is achieved. The performance of truncated microstrip patch antenna with DGS based on Double Looped CSRR array structure was also compared by replacing conventional proximity fed microstrip patch antenna with the same physical size. The conventional proximity coupled microstrip patch antenna is designed for a resonant frequency of $2.26 \mathrm{GHz}$ with a lower bandwidth of 23.3MHz. The antennas were designed using CST simulation software. The measurement results show a good agreement with simulated results
\end{abstract}

Copyright $\odot 2020$ Institute of Advanced Engineering and Science. All rights reserved.

\section{Corresponding Author:}

Thomaskutty Mathew,

Department of Physics, School of Technology,

GITAM University,

Bengaluru Campus, India

Email: thomaskutty.mathew@ gitam.edu

\section{INTRODUCTION}

Microstrip patch antenna are commonly used in wireless communication due to its reduced size, low cost low profile and compatibility with integrated circuits. Some of the advantages of microstrip antennas are lower cost of fabrication, compact, and lower sensitivity towards manufacturing tolerance [1]. Microstrip patch antennas have some inherent limitations such as smaller impedance bandwidth, low gain and single band operation [2,3]. Microstrip patch antennas for practical applications usually demanded size reduction and enhancement of bandwidth. One method to improve the bandwidth is to provide thicker substrate in between patch and the ground plane so as to increase the separation between them[4]. Other miniaturization methods applied on Microstrip patch antennas include Defected Ground Structure(DGS) on the ground plane[5,6], providing slots on patch, or combination of both[7], usage of high permittivity dielectric substrate etc[8]. For wideband communication systems microstrip patch antennas with DGS have been used nowadays. Defected ground structure (DGS) was discovered initially by Park et al., in 1999. DGS is accomplished by etching off some simple shape from the ground plane [9]. The development of microstrip antennas with DGS is detailed in [10-13]. The defected shape has to be changed for better performance. DGS structures includes square, octagonal, rectangular, concentric ring and also combined structures have been used [14]. The circular geometry of Split Ring Resonator (SRR) was proposed by Pendry et.al.,in [15]. 
Afterwards a quantitative methodology for analyzing the effective permeability and permittivity of metamaterials was proposed by Smith et al.,[16] in the year 2000 where the unit cell analyzed was square SRR. Later on the detailed study on design, fabrication and testing of DNG metamaterials of square SRR was conducted by Zilkowski in 2003 [17].

In this paper, truncated microstrip patch antenna with DGS based on Double Looped Complementary Split Ring Resonator (CSRR) arrays for enhancement of bandwidth is presented. The advantages of proximity coupled feeding method include higher bandwidth, better impedance matching and lower spurious radiation. In the proximity coupled feeding method, radiating patch is positioned on the top of the upper substrate and feed line is positioned in between two dielectric substrates [18]. Electromagnetic field coupling occurs between feed network and the patch. Higher bandwidth is the main advantage of this feeding method as compared to other feeding mechanisms. Bandwidth enhancement is obtained by using double looped structure in the ground plane. Bandwidth enhancement is achieved by etching this double looped CSRR array structure from the ground plane of the proposed truncated microstrip patch antenna. Some techniques used to enhance the bandwidth are summarized below.

The feed line is proximity-coupled with the patch antenna, which is printed on a superstrate will enhance the bandwidth[19]. Bandwidth enhancement is also achieved by Identical Dual Patch Microstrip Antenna with Air-Gap (IDMA) by increasing the overall thickness of microstrip patch anenna. and this method also provides air gap to reduce the effective permittivity [20]. Another method of bandwidth enhancement is achieved by varying the length of the dipole element [21]. The bandwidth of microstrip antenna is also increased by proximity fed method with stub loading at different locations [22]. Another method of increasing the bandwidth of rectangular microtrip patch antenna is to provide some slots in the non radiating area of the same patch [23]. Bandwidth enhancement is also achieved by cutting slots, so as to obtain the required hexagonal patch [24]. In the proposed work, proximity coupled feeding method is carried out with radiation patch which is placed on the top of the upper substrate and feed line is positioned in between the two substrates.

\section{ANTENNA DESIGN AND SIMULATION RESULTS}

\subsection{Conventional Proximity coupled microstrip patch antenna.}

The proposed geometry of the conventional proximity coupled microstrip patch antenna is depicted in Figure 1. The antenna structure is designed using FR-4 substrate with thickness $1.6, \varepsilon r=4.4$ and loss tangent is 0.02 . Figure 2 shows the simulated variation of return loss with frequency characteristics of the proposed antenna. The resonant frequency of the antenna is $2.26 \mathrm{GHz}$. The optimized design parameters of the antenna using CST Microwave studio are WS1 $=80 \mathrm{~mm}, \mathrm{WS} 2=40 \mathrm{~mm}, \mathrm{LS} 2=40 \mathrm{~mm}, \mathrm{LS} 1=80 \mathrm{~mm}$, feed length $=40 \mathrm{~mm}$ and width of the feed line $=2.4 \mathrm{~mm}$. Figure 3 represents the simulated surface current plot of the antenna at $2.26 \mathrm{GHz}$. Table1 represents the simulated values of conventional proximity coupled microstrip patch antenna.

Bandwidth is calculated from the $\mathrm{S} 11$ plot (-10dB return loss bandwidth). The difference between upper cutoff frequency $(2.2714 \mathrm{GHz})$ and lower cutoff frequency $(2.2481 \mathrm{GHz})$ is $0.0233 \mathrm{GHz}$ so bandwidth is $23.3 \mathrm{MHz}$. From Table 1, we can infer that bandwidth is narrow.

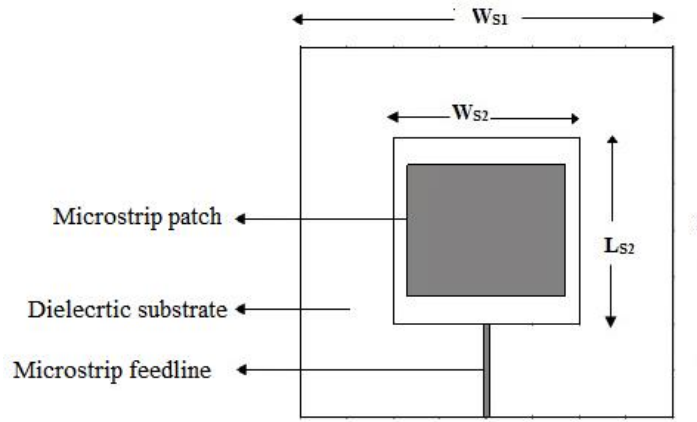

a) Top View

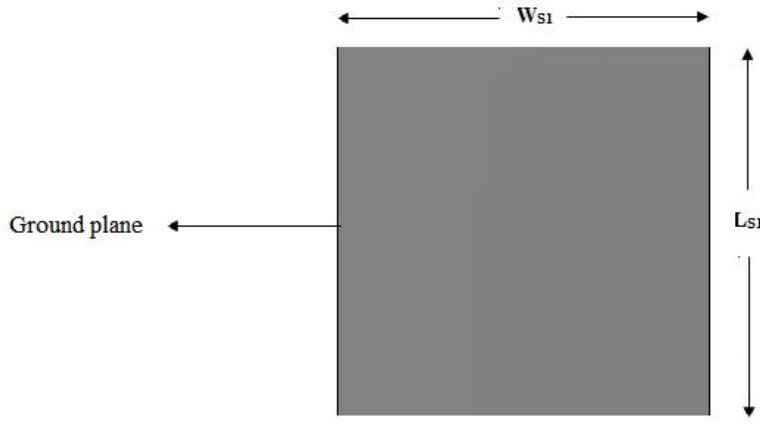

b) Bottom View

Figure 1. Geometry of the conventional proximity coupled microstrip patch antenna. 


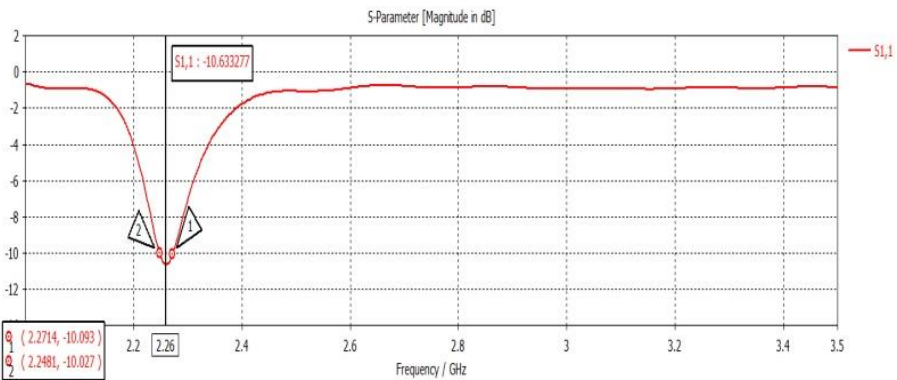

Figure 2. Simulated return loss variation with frequency of the proposed conventional microstrip antenna at $2.26 \mathrm{GHz}$.

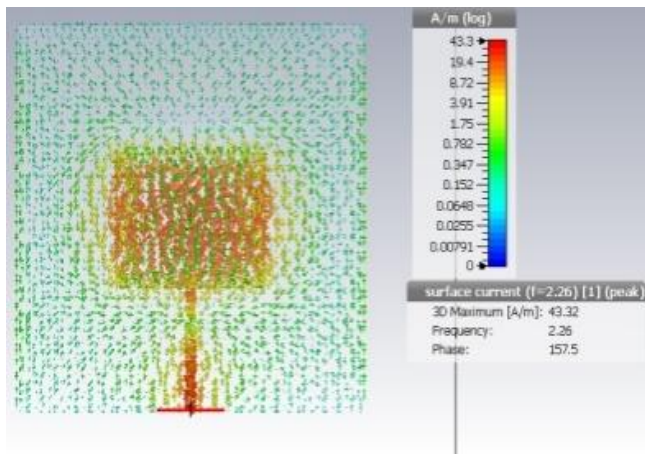

Figure 3. Simulated surface current distribution of the antenna at $2.26 \mathrm{GHz}$

Table 1. Simulated values of conventional proximity coupled microstrip patch antenna.

\begin{tabular}{cll}
\hline Sr.No & \multicolumn{1}{c}{ Parameters } & \multicolumn{1}{c}{ Value } \\
\hline 1 & Shape of ground & Without DGS \\
2 & Shape ofpatch area & Rectangular \\
3 & Returnloss $(\mathrm{dB})$ & -10.63 \\
4 & Frequency $(\mathrm{GHz})$ & 2.26 \\
5 & Bandwidth $(\mathrm{MHz})$ & 23.3 \\
6 & Bandwidth $(\%)$ & 1.3 \\
7 & Directivity $(\mathrm{dBi})$ & 6.97 \\
\hline
\end{tabular}

\subsection{Proximity coupled truncated microstrip patch antenna without DGS}

The truncated microstrip patch antenna without DGS is fabricated using two FR-4 substrates with $\varepsilon_{\mathrm{r}}=4.4$, and thickness $1.6 \mathrm{~mm}$. The geometrical view of the designed structure is depicted in Figure 4. The dimensions of the antenna are (unit: $\mathrm{mm}$ ), WS1 $=80 \mathrm{~mm}, \mathrm{WS} 2=40 \mathrm{~mm}, \mathrm{LS} 2=40 \mathrm{~mm}, \mathrm{LS} 1=80 \mathrm{~mm}$, with feed length $40 \mathrm{~mm}$ and width of the feed is $2.4 \mathrm{~mm}$. Figure 5 shows the simulation results of return loss plot of the antenna and Figure 6 represents the surface current plot of the antenna at lower and upper resonant frequencies. Table 2 represents the simulated values of truncated microstrip patch antenna without DGS.

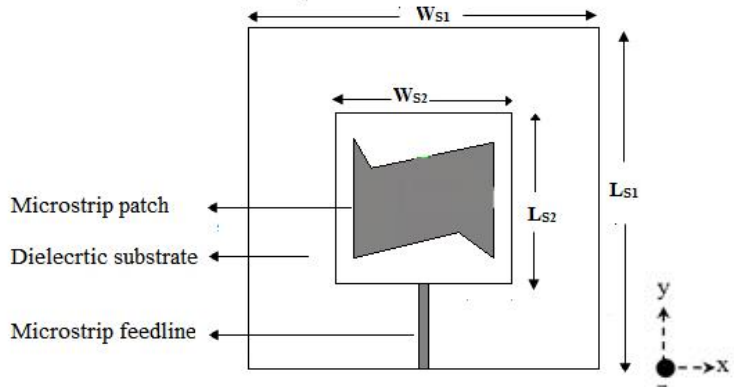

a) Top View

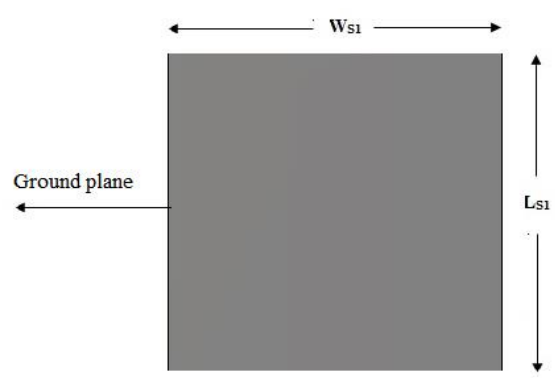

b) Bottom View

Figure 4. Geometry of the proposed antenna structure without DGS 


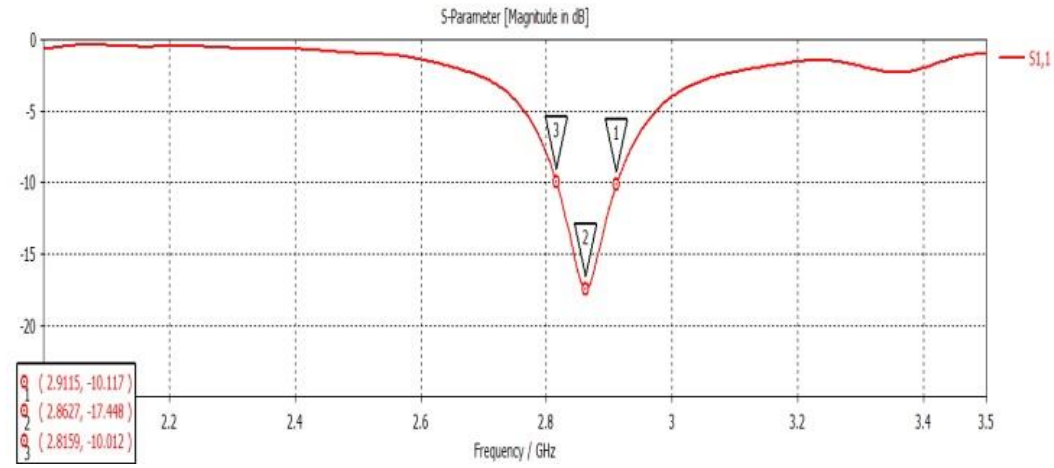

Figure 5. Simulated return loss characteristics of the proposed antenna resonating at $2.86 \mathrm{GHz}$.

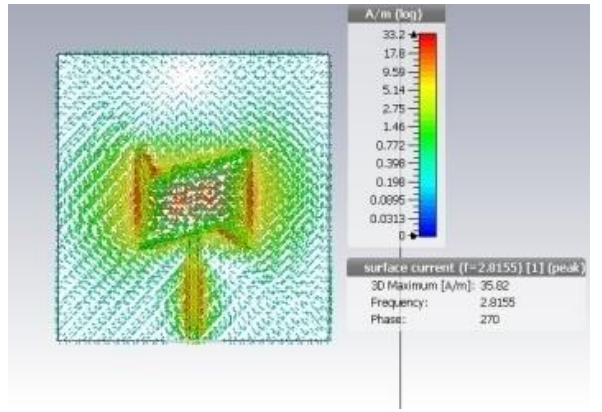

a)

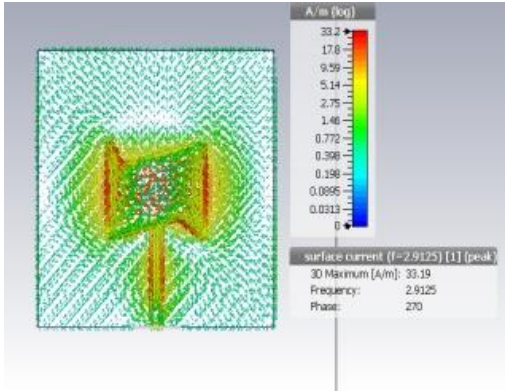

b)

Figure 6. Surface current plot of the antenna (a) at $2.81 \mathrm{GHzand}(\mathrm{b})$ at $2.91 \mathrm{GHz}$.

Table 2. Simulated values of proximity coupled truncated microstrip patch antenna without DGS.

\begin{tabular}{clc}
\hline Sr.No & \multicolumn{1}{c}{ Parameters } & Value \\
\hline 1 & Shape of ground & Without DGS \\
2 & Shape of patch area & Truncated \\
3 & Return loss $(\mathrm{dB})$ & -17.44 \\
4 & Frequency $(\mathrm{GHz})$ & 2.86 \\
5 & Bandwidth $(\mathrm{MHz})$ & 95.6 \\
6 & Bandwidth $(\%)$ & 3.38 \\
7 & Directivity $(\mathrm{dBi})$ & 7.21 \\
\end{tabular}

Bandwidth is calculated from the S11 plot (-10dB return loss bandwidth). The difference between upper cutoff frequency $(2.9115 \mathrm{GHz})$ and lower cutoff frequency $(2.8159 \mathrm{GHz})$ is $0.0956 \mathrm{GHz}$ so bandwidth is 95.6MHz. By comparing Table 1 and Table 2, we can infer that and bandwidth is increased and also by comparing Figure 1 and 4, we can infer that the patch size is reduced.

\subsection{Proximity coupled Truncated microstrip patch antenna with DGS based on Double Looped CSRR arrays for enhancement of Bandwidth.}

The truncated microstrip patch antenna with DGS based on Double Looped CSRR array structure gives better results as compared to truncated microstrip patch antenna without DGS. The truncated microstrip patch antenna with DGS based on Double Looped CSRR arrays is also fabricated using two FR4 substrates with $\varepsilon_{\mathrm{r}}=4.4$ and thickness $1.6 \mathrm{~mm}$. Geometrical representation of the antenna with DLCSRR structure is depicted in Figure 7. The substrate and patch dimensions of the proposed antenna is same as that of the previous antenna structure without DGS. The dimensions of DLCSRR structure are as follows (unit: $\mathrm{mm}$ ), $\mathrm{LS} 1=\mathrm{LS} 2=12.72, \mathrm{~g}=0.3$ and the width of both inner and outer loops are $0.5 \mathrm{~mm}$ each. The return loss characteristics are depicted in Figure 8. The current distribution of the antenna at lower and upper resonant frequencies are depicted in Figure 9. Table 3 represents the simulated values of truncated microstrip patch antenna with DGS based on Double Looped CSRR arrays. 


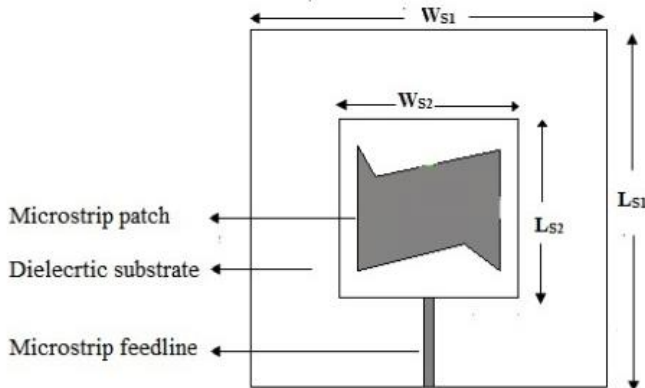

a) Front View

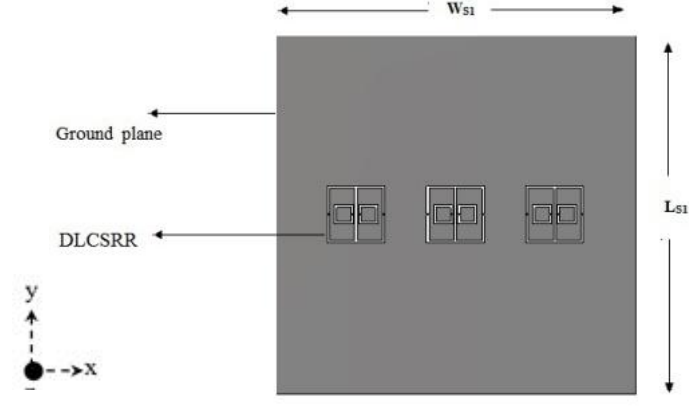

b) Back View

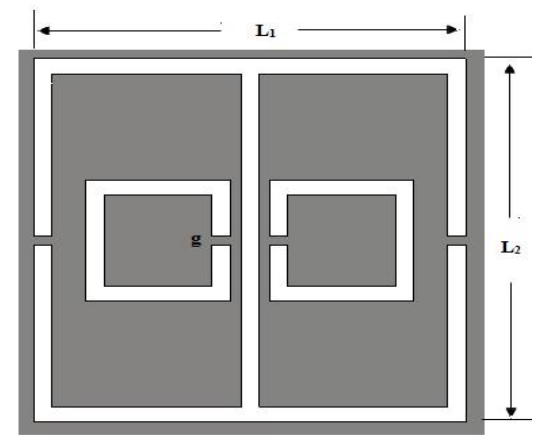

c) Single DLCSRR structure

Figure 7. Geometry of the truncated microstrip patch antenna with DGS based on Double Looped CSRR arrays.

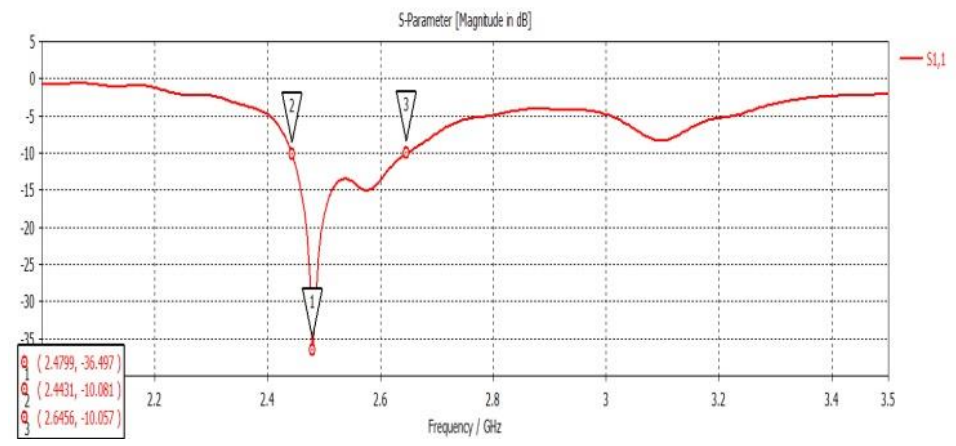

Figure 8. Simulated variation of return loss with frequency of the truncated microstrip patch antenna with DGS based on Double Looped CSRR arrays resonating at $2.47 \mathrm{GHz}$.

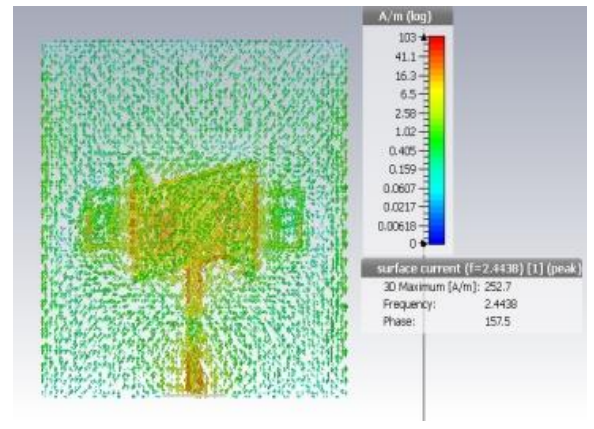

a)

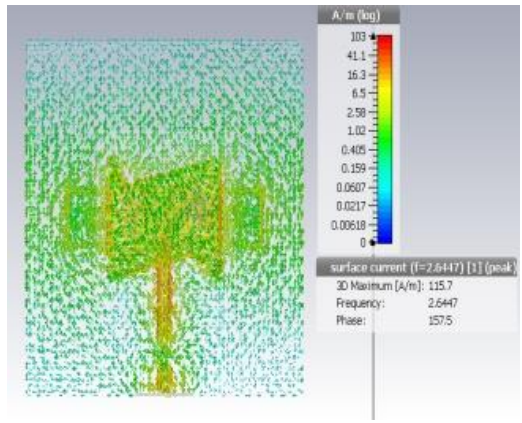

b)

Figure 9. Surface current distribution of the proposed truncated microstrip patch antenna with DGS based on Double Looped CSRR arrays (a) at lower resonant frequency and (b) at upper resonant frequency.

Bandwidth is calculated from the S11 plot (-10dB return loss bandwidth). The difference between upper cutoff frequency $(2.6456 \mathrm{GHz})$ and lower cutoff frequency $(2.4431 \mathrm{GHz})$ is $0.2025 \mathrm{GHz}$,so bandwidth is

Truncated Microstrip Patch Antenna with DGS based on Double Loop CSRR Arrays ... (Ajay V. G. et al) 
202.5MHz. By comparing Table 2 and Table 3, we can infer that 52.79\% bandwidth enhancement is achieved with considerable reduction in antenna size.

Table 3. Simulated values of proximity coupled truncated microstrip patch antenna with DGS based on Double Looped CSRR arrays

\begin{tabular}{rlr}
\hline Sr.No & \multicolumn{1}{c}{ Parameters } & Value \\
\hline 1 & Shape of ground & DLCSRR \\
2 & Shape of patcharea & Truncated \\
3 & Return loss $(\mathrm{dB})$ & -36.49 \\
4 & Frequency $(\mathrm{GHz})$ & 2.47 \\
5 & Bandwidth $(\mathrm{MHz})$ & 202.5 \\
6 & Bandwidth $(\%)$ & 8.16 \\
7 & Directivity $(\mathrm{dBi})$ & 6.67 \\
\hline
\end{tabular}

\section{RESULTS AND ANALYSIS}

The truncated microstrip patch antenna without and with DGS based on Double Looped CSRR arrays was fabricated and measurements were taken in the laboratory. The fabricated prototypes of the proposed antennas are illustrated in Figure 10 and Figure 11. The radiation pattern of the proposed antennas are measured in anechoic chamber and the return loss characteristics are measured using Agilent PNA series Network analyzer N5230A(10MHz to $50 \mathrm{GHz})$. Figure 12 and Figure 13 represent the characteristics of simulated and measured values of return loss variation with frequency of the antenna without DGS and with DGS based on Double Looped CSRR arrays. A small variation arises between simulated and measured values because in the simulation, the antenna is excited using a waveguide port, but practically the antenna is excited using the SMA connector. The connector loss has an effect on the response of the antennaThe simulated and measurement results of the proposed truncated microstrip patch antenna with DGS based on Double Looped CSRR arrays shows that the bandwidth enhancement is achieved as compared with other two structures. Figure 14 represents the measured radiation pattern of truncated microstrip patch antenna with DGS based on Double Looped CSRR arrays at 2.6GHz. Comparison chart of the proximity coupled truncated microstrip patch antenna without and with DGS based on Double Looped CSRR arrays is shown in Table 4. The simulated and measured values of gain w.r.t. proximity coupled truncated microstrip patch antenna without DGS are $5.69 \mathrm{~dB}$ and $4.21 \mathrm{~dB}$ and truncated microstrip patch antenna with Double Looped CSRR arrays are $4.21 \mathrm{~dB}$ and $4.03 \mathrm{~dB}$ respectively

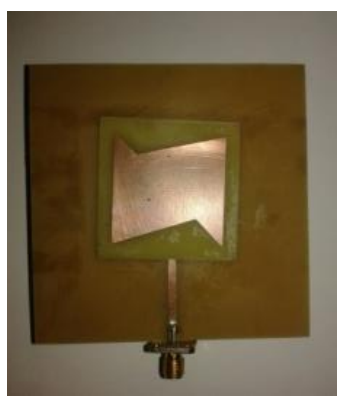

a) Front View

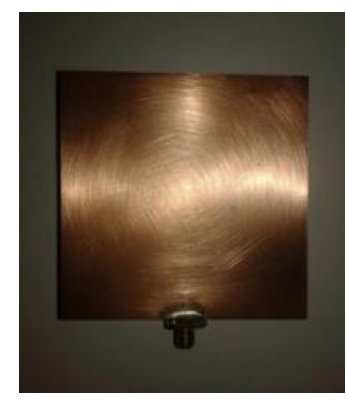

b) Back View

Figure 10. Prototype of the proposed truncated microstrip patch antenna without DGS.

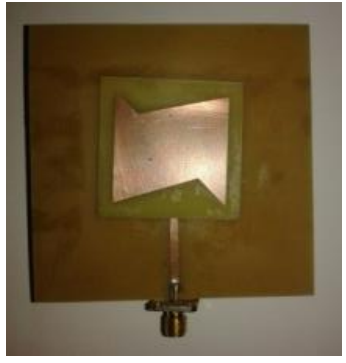

a) Front View

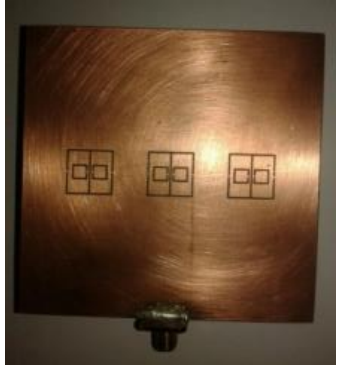

b) Back View

Figure 11. Prototype of the proposed truncated microstrip patch antenna with DGS based on Double Looped CSRR arrays. 


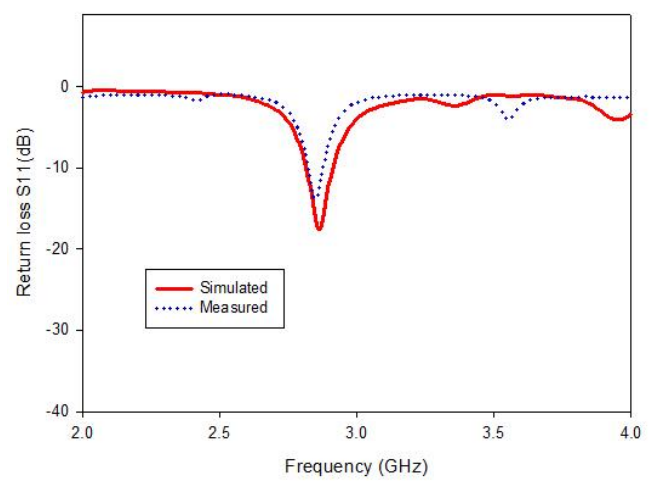

Figure 12. Simulated and measured variation of return loss characteristics of the antenna without DGS.

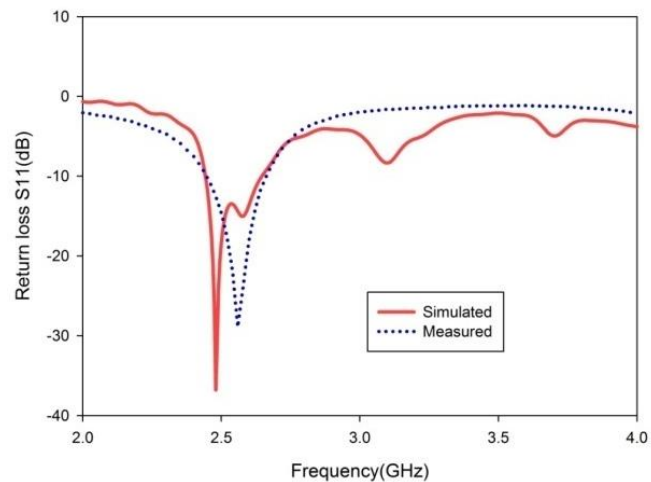

Figure 13. Simulated and measured variation of return loss characteristics of the truncated microstrip patch antenna with DGS based on Double Looped CSRR arrays.

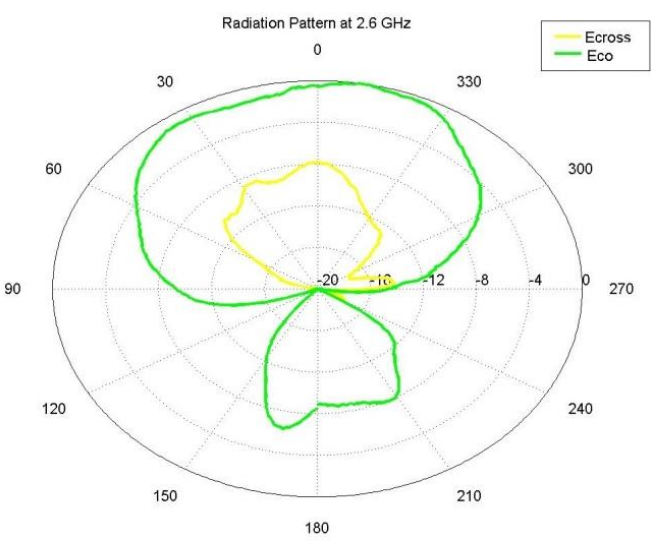

a) E plane pattern

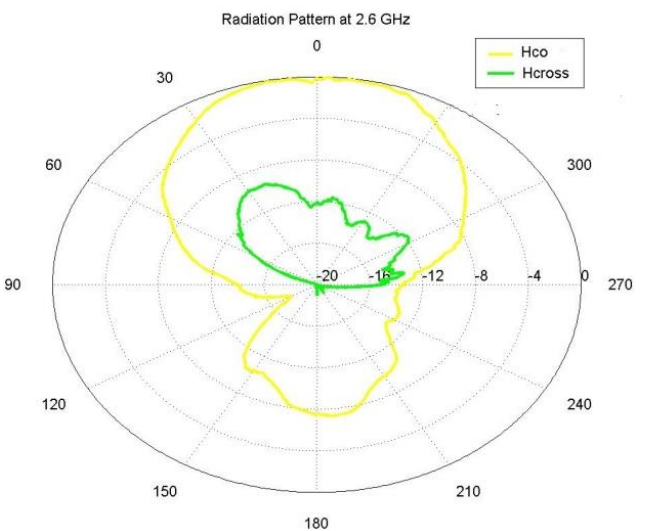

b) H Plane Pattern

Figure 14. Measured radiation pattern of the truncated microstrip patch antenna with DGS based on Double Looped CSRR arrays.

Table 4. Comparison chart of the truncated microstrip patch antenna without and with DGS based on Double Looped CSRR arrays.

\begin{tabular}{ccccccc}
\hline $\begin{array}{c}\text { Shape in } \\
\text { ground }\end{array}$ & \multicolumn{2}{c}{$\begin{array}{c}\text { Frequency } \\
(\mathrm{GHz})\end{array}$} & \multicolumn{2}{c}{$\begin{array}{c}\text { Bandwidth } \\
(\mathrm{MHz})\end{array}$} & $\begin{array}{c}\text { Return loss } \\
\text { (Minimum) }\end{array}$ \\
\hline \multirow{2}{*}{ Without DGS } & 2.86 & 2.84 & 95.60 & 61.66 & -17.44 & Measured \\
With DGS & 2.47 & 2.56 & 202.5 & 193.05 & -36.49 & -36.78 \\
\hline
\end{tabular}


From Table 4, the measured results indicate $63.06 \%$ percentage increase in bandwidth along with size reduction is achieved with truncated microstrip patch antenna with DGS based on Double Looped CSRR arrays as compared to the truncated microstrip patch antenna without DGS.

Several simulation studies are conducted on truncated microstrip patch antenna at different positions and combinations of different CSRR structures in the ground plane. As per the comparison results, the proximity fed truncated microstrip patch antenna without DGS and with DGS based on three DLCSRRs provides optimized results. A comparison between the proposed work and published work is tabulated in Table 5. As per the comparison, the proposed Truncated microstrip patch antenna with DGS based on Double Looped CSRR arrays achieves bandwidth enhancement.

Table 5. Comparison chart of the proposed antenna and published papers

\begin{tabular}{lc}
\hline \multicolumn{1}{c}{ Paper } & Bandwidth enhancement in percentage \\
\hline Reference no. [21] & $12 \%$ \\
Reference no. [22] & $23.6 \%$ \\
$\begin{array}{l}\text { Proposed Truncated Microstrip Patch Antenna with DGS Based on } \\
\text { Double Looped CSRR Arrays for Enhancement of Bandwidth }\end{array}$ & $52.79 \%$
\end{tabular}

\section{CONCLUSION}

Truncated microstrip patch antenna with DGS based on Double Looped CSRR arrays has been designed, fabricated and compared its performance with truncated microstrip patch antenna without DGS. From the simulated and measured results, it is observed that the truncated microstrip patch antenna with DGS based on Double Looped CSRR arrays achieved the percentage increase bandwidth of 52.79\% and 63.06\% respectively as compared to truncated proximity coupled microstrip patch antenna without DGS. The proposed antenna is suitable for WLAN/Wi-Fi and RFID applications.

\section{REFERENCES}

[1] A Constantine A Balanis. Antenna Theory: Analysis and Design. 3rd ed. John Wiley \& Sons, Inc. 2005.

[2] Khan, M. U., M. S. Sharawi, and R. Mittra, "Microstrip patch antenna miniaturisation techniques:A review," IET Microwaves, Antennas and Propagation, Vol. 9, No. 9, 913-922, 2015.

[3] Lee, K. F. and K. F. Tang, "Microstrip patch antenna - Basic characteristics and some recent advances," Proceedings of the IEEE, Vol. 100, 2169-2180, July 2012.

[4] A A Abdelaziz. Bandwidth Enhancement of Microstrip Antenna. Progress in Electromagnetics Research (PIER). 2006; 63: 311-317.

[5] Chakraborty, M., B. Rana, P. Sarkar, and A. Das, "Size reduction of microstrip antenna with slots and defected ground structure," International Journal of Electronics Engineering, Vol. 4, No. 1,61-64, 2012

[6] Elftouh, H., N. A. Touhami, M. Aghoutane, S. El Amrani, A. Tazon, and M. Boussouis,"Miniaturized microstrip patch antenna with defected ground structure," Progress In Electromagnetics Research C, Vol. 55, 25-33, 2014.

[7] Mukesh Kumar Khandelwal, Binod Kumar Kanaujia, and Sachin Kumar, "Defected Ground Structure: Fundamentals, Analysis, and Applications in Modern Wireless Trends" International Journal of Antennas and Propagation, Volume 2017, Article ID 2018527, 22 pages

[8] Lo, Terry Kin-chung, Yeongming Hwang. Microstrip antennas of very high permittivity for personal communications. Asia Pacific Microwave Conference. Hong Kong. 1997; 1:253-256.

[9] Mrs.Devashree S.Marotkar, Dr.Prasanna Zade,"Bandwidth Enhancement of Microstrip Patch Antenna using Defected Ground Structure" Proceedings of the International Conference on Electrical, Electronics, and Optimization Techniques (ICEEOT) - 2016

[10] D. Guha, S. Biswas, and Y. M. M. Antar, Defected Ground Structure for Microstrip Antennas, in Microstrip and Printed Antennas: New Trends, Techniques and Applications, John Wiley \& Sons, London, UK, 2011.

[11] R. Garg, I. Bahl, and M. Bozzi, Artech House, Artech House, Norwood, Mass, USA, 3rd edition, 2013.

[12] J. G. Webster, Ed., Wiley Encyclopedia of Electrical and Electronics Engineering, John Wiley \& Sons, Hoboken, NJ, USA, 2001, 2013 (Online update).

[13] K. Fujimoto and H. Morishita, Modern Small Antennas, chapter 8, Cambridge University Press, 2013. View at Publisher · View at Google Scholar

[14] Ashwini K Arya, M V Kartikeyan, A Patnaik. "Defected Ground Structure in the perspective of Microstrip Antennas A Review". Article in Frequenz Berlin. 2010: 79-84.

[15] J.B. Pendry, AJ. Holden, D.J. Ribbins, and WJ. Stewart, "Magnetism from conductors and enhanced nonlinear phenomenon,” IEEE Trans. Microwave Theory Tech., vol.47,2075-2084, Nov. 1999. 
[16] D. R. Smith, W. J. Padilla, D. C. Vier, S. C. Nemat-Nasser, and S. Schultz "Composite medium with simultaneously negative permeability and permittivity," Phys. Rev. Lett., vol. 84, pp. 4184-4187, 2000.

[17] R. W. Ziolkowski, "Design, fabrication, and testing of double negative metamaterials," IEEE Trans. Antennas Propagat., vol.51, pp. 2572-2581,2003.

[18] Dawit Fistum, Dilip Mali, Mohammed Ismail, "Bandwidth Enhancement of Rectangular Microstrip Patch Antenna using Defected Ground Structure". Indonesian Journal of Electrical Engineering and Computer Science Vol. 3, No. 2, August 2016, pp. $428-434$

[19] D.M.Pozar and B. Kaufman, "Increasing the bandwidth of a microstripantenna by proximity coupling", Electron.Lett.,vol.23,no.8, pp.368-369, Apr. 1987

[20] RSA Raja Abdullah, D. Yoharaaj and Alyani Ismail, "Bandwidth enhancement technique in microstrip antenna for wireless applications",PIERS Online,Vol. 2, No. 6, 2006, pp. 633-639.

[21] A.Abdelaziz, "Bandwidth enhancement of microstrip antenna", Progress In Electromagnetics Research, PIER 63, 2006, pp. 311-317.

[22] P.K. Singhal and L. Shrivastava, "On the investigations of a wide band proximity fed bow tie shaped microstrip antenna", Journal of Microwave and Optoelectronics, Vol. 3, pp. 87-98, April 2004.

[23] S. S. YAvalkar, R. T. Dahatonde, S. S. Rathod and S. B. Deosrkar, "Comparative analysis of bandwidth enhancement of microstrip patchantennas using various geometries", IOSR Journal of Electronics and Communication Engineering (IOSR-JECE), Vol. 3, Issue. 4, (Sep-Oct.2012), pp. 15-18.

[24] Priyanka and Navin Srivastava, "Bandwidth enhancement for microstrip patch antenna using suspended techniques for wireless applications",International Journal of Advancements in Research and Technology, Vol. 2, Issue. 5, May-2013 pp. 231-235 